\title{
A IMPORTÂNCIA DAS CIÊNCIAS HUMANAS, LETRAS E ARTES NA SOCIEDADE TECNOLÓGICA CONTEMPORÂNEA' ${ }^{1}$
}

\author{
THE IMPORTANCE OF HUMAN SCIENCES, LETTERS AND \\ ARTS IN CONTEMPORARY TECHNOLOGICAL SOCIETY
}

Cleber Gibbon Ratto2

Recebido em: 10 de março de 2017

Aprovado em: 30 de junho de 2017

Sistema de Avaliação: Double Blind Review

RPR | a.14 | v.2 | p.61-75 | jul./dez. 2017

\section{RESUMO}

O presente texto apresenta a versão revisada da Conferência proferida por ocasião da Aula Magna do ICHLA/FEEVALE em abril de 2017. O texto trata de explorar a problemática da importância das humanidades, letras e artes para a cultura atual, notadamente marcada pela presença maciça das tecnologias e suas consequências psicossociais. Ao modo de um ensaio teórico, divide-se em duas partes: a) o lugar das Ciências Humanas na atualidade e; b) desafios político-cognitivos do presente. Desenvolve a tese segundo a qual a função social das humanidades, letras e artes na atualidade depende da afirmação de novas condições internas da própria ciência, quais sejam: capacidade de relativismo esclarecido e diálogo transdisciplinar. Além disso, sustenta a necessidade de colocar em ação atitudes político-cognitivas bastante escassas entre nós em tempos de tamanha aceleração e competitividade: reanimar o futuro, exercer memórias e amar o presente, com toda a concentração e o cuidado que ele merece.

Palavras-chave: Ciências humanas. Letras. Artes. Cultura. Contemporaneidade.

\begin{abstract}
This text presents the revised version of the lecture given at the ICHLA/FEEVALE Aula Magna in April 2017. The text tries to explore the problematic of the importance of the humanities, letters and arts to the current culture, especially marked by the massive presence of technologies and their psychosocial consequences. In the manner of a theoretical essay, it is divided into two parts: a) the place of the Human Sciences in the present and; b) political-cognitive challenges of the present. It develops the thesis according to which the social function of the humanities, letters and arts in the present time depends on the affirmation of new internal conditions of the science itself, which are: capacity of enlightened relativism and transdisciplinary dialogue. In addition, it supports the need to put into action rather scarce political-cognitive attitudes among us in times of such acceleration and competitiveness: to reanimate the future, to exercise memories and to love the present, with all the concentration and care that it deserves.
\end{abstract}

Keywords: Human sciences. Letters. Arts. Culture. Contemporaneity.

\footnotetext{
${ }^{1}$ Versão revisada da Conferência proferida por ocasião da Aula Magna do Instituto de Ciências Humanas, Letras e Artes da Universidade Feevale, no dia 18 de abril de 2017.

${ }^{2}$ Doutor em Educação pela Pontifícia Universidade Católica do Rio Grande do Sul (Porto Alegre/Brasil). Professor na Universidade La Salle (Canoas/Brasil).E-mail: cleber.ratto@unilasalle.edu.br.
} 


\section{INTRODUÇÃO}

Quero agradecer incialmente aos colegas do Instituto de Ciências Humanas, Letras e Artes da Universidade FEEVALE - o ICHLA - pelo convite e pela confiança em mim depositada para a condução desta Aula Magna.

Sinto-me honrado pelo convite e ao mesmo tempo responsabilizado pela tarefa que me coube, de articular algumas reflexões em torno da importância das Ciências Humanas, das Letras e das Artes naquilo que convencionamos chamar de Sociedade Tecnológica Contemporânea. Essa frase intitula a minha fala e ao mesmo tempo demarca uma espécie de problemática inicial, sobre a qual eu me debrucei para escrever este texto e organizar as ideias para esta fala.

Parto, então, dessa pergunta: Qual será, afinal, a importância das Ciências Humanas, das Letras e das Artes neste tempo tão complexo e controverso que é o nosso?

Complexo porque marcado por uma infinidade de forças políticas, econômicas, culturais, sociais, enfim... por uma profusão de tempos que convergem para o nosso tempo e nele se encontram, fazendo da atualidade esse campo de constantes tensões e disputas entre diferentes projetos de mundo e de humanidade. Assim é que desejo me referir ao contemporâneo, esse tempo para onde todos os tempos convergem, nos colocando na con/fluência e na con/vivência do arcaico, da tradição, do moderno, do atual e do que se desenha como futuro. Todos os tempos, cada qual com suas forças, neste tempo que é o nosso: daí a sua complexidade.

Controverso porque marcado por uma variedade de interpretações que disputam por dar sentido ao que estamos vivendo. Para alguns, o tempo da decadência cultural, do escândalo moral e do fracasso político. Para outros, tempo de revolta e transformação, supostamente o ocaso de uma Era e a emergência de outras formas de existir e conviver. Para outros, ainda, um tempo de travessia, de criação e/ou de desgraça potencial: um tempo à espera do nosso gesto.

Enfim, complexo e controverso ao mesmo tempo.

De qualquer forma, é neste tempo que nos tocou viver e é com ele que precisamos nos ver, todos nós, educadores, cientistas, artistas, escritores, técnicos, gestores.

$\mathrm{O}$ que parece relativamente consensual, é que ao longo do século $\mathrm{XX}$, vimos desabar pouco a pouco todo esse sonho civilizatório calcado na Razão Esclarecida. A tecnologia ganha "vida própria" e ultrapassa os limites do imaginável, paradoxalmente, devolvendo à humanidade uma espécie de além ou aquém da razão esclarecida. A Ciência, na medida em que aguça os recursos de suas lupas e de seus telescópios no desvendamento do micro e do macrocosmo, reencontra-se constrangedoramente com a vastidão do próprio mundo, em sua imensidão e mistério.

O sonho do bem-estar oriundo do progresso, do domínio sobre as forças da natureza - fora ou dentro do próprio homem - compuseram o projeto oficial do pensamento moderno e da política que dele se alimenta. Segundo Giacoia Junior (2005, p. 102):

Tal como se atesta nessa inspiração dos pioneiros da moderna Aufklärung, um otimismo triunfalista está na base do credo científico desses pensadores: a razão, com base na ciência e na técnica, que dela decorre, pode enfrentar e resolver com sucesso os mais importantes problemas humanos, de modo a garantir o domínio sobre as forças da natureza, assim como realizar a justiça nas relações entre os homens.

Também as tecnologias da informação e da comunicação não foram capazes, por si sós, de realizar essa promessa de emancipação e progresso a serviço do bem comum. O mundo das desejáveis e inevitáveis tecnologias de informar e comunicar, de transportar e de aproximar homens e mulheres é, também, e ainda hoje, o mundo dos reiterados conflitos bélicos, do terrorismo de Estado, dos conflitos 
étnicos exacerbados, da intolerância religiosa e existencial. Nossas pretensões democráticas comunicativas encontram barreiras bastante firmes na indisposição de grandes nações ao diálogo conciliatório, tudo em nome do progresso, da segurança e da suposta inevitabilidade do capitalismo competitivo nos mercados globalizados.

Assim, dividirei essa minha fala, basicamente, em dois blocos: o primeiro, mais curto e pontual, em torno do lugar das Ciências Humanas neste contexto e; o segundo, mais desdobrado e reflexivo, feito de três imagens, que vou chamar aqui de desafios político-cognitivos, em torno da necessária reabilitação da nossa capacidade de pensar, de sentir e de agir no presente. Essas imagens serão tentativas de dar forma àquelas que seriam condições da própria função social das Ciências Humanas, neste tempo complexo e controverso que é o nosso. Então, mãos à obra!

\section{PRIMEIRA PARTE: AS CIÊNCIAS HUMANAS HOJE}

Farei uma breve demarcação daquilo que chamaremos aqui de Ciências Humanas, ou Ciências do Espírito como quer a tradição, para em seguida me ocupar daqueles desafios político-cognitivos que eu gostaria de enfrentar com vocês nesta noite.

No que consistiriam mais propriamente as chamadas Ciências Humanas?

Longe de tentar traçar aqui uma espécie de genealogia do campo, o que seria impróprio e demasiado pretensioso para uma fala como essa, vou me servir das observações muito precisas e pertinentes de um filósofo alemão chamado Wolfgan Welsch, professor de filosofia na Universidade Friedrich Schiller em Jena/Alemanha, num texto publicado originalmente em 1998 e traduzido/publicado para o português em 2007. O texto se chama "Mudança estrutural nas ciências humanas: diagnóstico e sugestões".

Há um pressuposto neste texto, que é o seguinte: As "Ciências Humanas" não são - em resumo nem internamente subdivididas com precisão, nem têm uma delimitação clara em relação ao exterior. Sua interdependência se deve não à referência a um elemento aparentemente unificador - como "espírito"-, mas a diversas sobreposições e parentesco entre as disciplinas. Elas são articuladas de uma maneira definida por Wittgenstein através do conceito de "semelhanças de família" (WELSCH, 2007).

E exatamente nisso consiste a força, e não a fragilidade, das Ciências Humanas.

Em linhas gerais, esse texto sustenta o seguinte argumento de que: "em meio aos problemas do mundo de hoje apenas se corresponderem aos novos padrões internos da ciência, as Ciências Humanas conseguirão cumprir sua tarefa extracientífica, sua tarefa social” (WELSCH, 2007, p.254).

Note-se que aqui há dois elementos-chave: novos padrões internos da ciência e sua tarefa social. Por novos padrões internos da ciência, Welsch está se referindo a duas dimensões características do pensamento científico contemporâneo: 1) o reconhecimento do relativismo e; 2) a irresistível demanda por transdisciplinaridade.

A primeira - reconhecimento do relativismo - que ele nomeia muito apropriadamente como "relativismo esclarecido" diz respeito ao fato de que "a validade das constatações feitas no interior de uma versão de mundo é, então, relativa às premissas dessa versão: no contexto das premissas escolhidas, as afirmações fazem sentido; no contexto de outras premissas, não. Na ciência deve-se, portanto, sempre enunciar as condições em função das quais uma afirmação adquire sua validade" (WELSCH, 2007, p.249)

Tal imagem de um relativismo epistemológico já está bastante disponível e disseminada no campo das ciências humanas. Entretanto, isso implicaria assumir uma postura que abdicaria da tarefa 
interpretativa e do esforço argumentativo de inteligibilidade de um determinado sistema de interpretação? Parece que não.

É o próprio filósofo quem questiona: "essa relatividade significa então (conforme se diz freqüentemente e talvez seja o seu temor) que tudo seja possível, tudo igual, tudo aleatório? Não, absolutamente. Pois no interior de uma versão de mundo, independentemente de sua complexidade, parece não se poder sustentar nada que seja aleatório" (WELSCH, 2007, p.249)

Com isso Welsch define essa primeira condição. As ciências humanas, assim como quaisquer outras, não podem pretender afirmar verdades sem antes demarcar seus critérios de validade. Verdades são válidas em determinadas condições, e mais, isso não equivale a dizer que tudo é válido, mas significa dizer que o trabalho de justificação ética e epistemológica é incontornável.

A segunda dimensão a que nos referimos anteriormente - a irresistível demanda por transdisciplinaridade - abre-se como um desafio epistemológico que é, ao mesmo tempo, ético e político. Refere-se a um modo próprio de conhecer, que implica antes de tudo um modo próprio de estar na relação consigo mesmo, com os saberes e com os demais sujeitos.

A característica de entrelaçamento das racionalidades exige a transição para uma perspectiva sob a forma da transdisciplinaridade. Apenas a transdisciplinaridade permite explorar legitimamente uma disciplina. Somente assim pode-se então realizar as esperanças legítimas da interdisciplinaridade. Esse é o estado do conhecimento hoje (...) a nova compreensão do entrelaçamento das racionalidades exige uma mudança correspondente da concepção das disciplinas científicas. Também elas não são, na verdade, fechadas, mas definidas por entrelaçamentos e perpassadas por transições. Isso implica em conseqüências de largo alcance para a organização da ciência (...) Instituições de pesquisa e universidades não deveriam mais classificar o campo do conhecimento conforme áreas de hegemonia territorial, domínios, disciplinas, especialidades, e sim elevar a transdisciplinaridade à categoria de princípio estrutural (WELSCH, 2007, p.244-245).

Sabemos bem o quanto isso é difícil e quanto as práticas sociais que encarnam a ciência estão distantes desse horizonte traçado pelo filósofo. Entretanto, também parece haver entre nós certo consenso de que este é o horizonte das formas do conhecimento, não exatamente porque queiramos, mas porque a realidade se impõe cada vez mais de contundente, com seus problemas, desafiando o confinamento e a segmentação dos saberes acadêmicos. Não é à toa que o relativismo e o elogio do desfazimento das fronteiras disciplinares, pelo menos em tese, marcam nossos projetos pedagógicos, documentos institucionais, perfis dos egressos, etc.

Grosso modo, partilhamos desse ideário de formação que envolve profissionais capazes de relativizar suas verdades, fazer a crítica dos discursos e das práticas dominantes, trabalhar, no mínimo, interdisciplinarmente ou em equipes multiprofissionais. Enfim, muitos são os sinais dessa nossa disposição (pelo menos em tese) de estarmos "mais juntos e misturados".

Independente disso, voltemos à afirmação de Welsch sobre o destino das Ciências Humanas: supõe-se que, em meio aos problemas do mundo de hoje, apenas se corresponderem aos novos padrões internos da ciência, as "Ciências Humanas" conseguiriam cumprir sua tarefa social, extracientífica.

Novos padrões internos da Ciência. Quais são, segundo ele? Relativismo esclarecido e transdisciplinaridade. Princípios que também defendemos e, em linhas gerais, servem de ideais das nossas práticas. Sermos capazes de relativizar nossas verdades e nossos saberes para uma abertura às verdades e aos saberes dos demais, com os quais podemos nós próprios nos constituirmos. Mas qual seria essa tarefa extracientífica das Ciências Humanas, sua função social hoje? Favorecer uma desejável e responsável transculturalização. 
As Ciências Humanas são, em diferentes sentidos, relacionadas a essa transição para a transculturalidade. Elas são parte ativa dessa transição. A transculturalidade tem validade hoje não apenas na macroesfera social, mas cada vez mais na microesfera dos indivíduos. Estamos nos tornando, em nossas próprias formações, cada vez mais transculturais. E nisso as Ciências Humanas são parte ativa - pelo menos para aqueles que com elas trabalham ou que são atingidos por elas (WELSCH, 2007).

Isso porque as Ciências Humanas abrem ou ampliam o conhecimento de diferentes tradições e manifestações culturais e podem, assim - intencionalmente ou não - levar ao entendimento de que algumas dessas "expressões" ou "manifestações" seriam para o próprio indivíduo mais produtivas e aceitáveis do que aquelas com as quais, por exemplo, ele foi educado em seu meio de origem. A isso se refere o próprio Welsch (1995) em textos anteriores como "estetização" da existência. Ou seja, cada um tem em maior ou menor grau a possibilidade de interferir sobre seu próprio destino cultural e produzir modos de viver que lhe pareçam mais ética ou moralmente convenientes.

Assim, podemos conceber que essa potencial produtividade política e subjetiva das Ciências Humanas, está diretamente relacionada ao modo como nós próprios as encarnamos em nossas práticas, em nossos modos de ser com os demais. O exercício de um relativismo esclarecido e de uma transdisciplinaridade são as condições para a efetivação da função social das Ciências Humanas, qual seja: uma abertura política (modo de estar com os outros na pólis) e subjetiva (modos de estar consigo mesmo) à transculturalização, ou seja, essa disposição para uma mistura ética (modos de viver) e estética (modos de sentir), que nos enriqueçam como Humanidade.

E isso parece estar mais atual e legítimo do que nunca, num tempo de acentuada inflação da intolerância e dos totalitarismos.

Assim eu fecho, então, essa primeira parte da minha intervenção. Resumindo: As Ciências Humanas - cuja demarcação não pode ser definitiva ou terminante - mas que se caracterizam por uma semelhança de famílias, só podem exercer com força sua função extracientífica (função social) de transculturalização, de ampliação do horizonte cultural humano e de suas formas de existência com os outros, na medida em que acolherem em seu interior uma disposição ao relativismo esclarecido e à transdisciplinaridade.

Ocorre que essas condições não são, ou não podem ser abstratas. São antes de mais nada, práticas sociais, que se materializam por gestos humanos, por modos de ser e estar-com-os-outros, por modos de existir. Implicam, assim: modos de pensar, modos de sentir e modos de agir.

\section{SEGUNDA PARTE: DESAFIOS POLÍTICO-COGNITIVOS NO PRESENTE}

Agora pretendo explorar com vocês algumas daquelas que eu chamarei aqui de condições político-cognitivos envolvidas no exercício dessas práticas sociais que encontramos em Welsch caracterizadas como relativismo esclarecido e transdisciplinaridade.

Diferentemente de tentar perseguir o sentido mesmo do que seja o relativismo ou a transdisciplinaridade, pretendo explorar aqui aqueles que me parecem constituir nos dias de hoje, na dita "sociedade tecnológica contemporânea" alguns dos maiores desafios político-cognitivos do nosso tempo. Diferentemente de argumentar em torno do que seria, em termos ideais, o relativismo esclarecido e a transdisciplinaridade, que nós temos muita dificuldade de exercer, quero me referir àquelas que parecem ser condições para caminharmos na direção disso.

Refiro-me aqui a condições muito mais "elementares", digamos assim, porque não se referem a um projeto "ideal" de conhecimento ou de formação nas Ciências Humanas, nas Letras e nas Artes, mas muito mais às práticas sociais cotidianas, que envolvem um certo modo de estar consigo e com os outros. 
Em última análise, um certo modo de pensar, de sentir e de agir, que está diretamente associado a um modo de ser em relação ao tempo.

Por que chamá-los, então, de desafios político-cognitivos?

Primeiro para demarcar que eles não são desafios apenas macropolíticos, no sentido de um projeto institucional, ou de governo, ou ainda um projeto de Estado. E segundo, para demarcar que também não se trata apenas de um desafio individual ou pessoal, que cada pode assumir por sua conta, como se fosse o bastante "fazer a sua parte".

Nem uma coisa nem outra: não se trata de esperar que haja a instituição de condições objetivas para que isso aconteça, de um lado, e nem de imaginar que cada um pode realizar isso apenas por sua conta por decisão ou vontade individual. $\mathrm{O}$ enfrentamento desses desafios implica aquilo que seriam condições intersubjetivas, ou seja, certos modos de estar junto, de nos relacionarmos, de ser-com-osoutros, que o ambiente pode favorecer, mas não garantir. Que nós também podemos favorecer, mas não garantir. São desafios das relações, que se aplicam a nós, praticantes das ciências humanas, mas também àqueles para os quais nossos saberes, nossos discursos e nossas práticas se destinam.

Assim, nosso foco aqui estará sobre os modos de nos relacionarmos, de viver junto, de ser-comos-outros, atravessados transversalmente por um elemento que articula esses três desafios: nossa relação com o tempo.

Partilho aqui da compreensão de Walter Benjamin (2010), de que a marca do capitalismo moderno é a aceleração do tempo. Aceleração essa que, na contemporaneidade, assume sua forma extrema. Já não podemos parar, e nisso consiste uma espécie de "golpe" político-subjetivo que nos aliena sobretudo de nós mesmos, de nosso corpo, em suma, de nossa potência política de agir no presente. "Marx diz que as revoluções são a locomotiva da história universal. Mas talvez as coisas se passem de maneira diferente. Talvez as revoluções sejam o gesto de acionar o travão de emergência por parte do gênero humano que viaja nesse comboio" (BENJAMIN, 2010, p.177).

Nietzsche já havia advertido, em sua aguda crítica ao ethos moderno, acerca dos padecimentos de uma sociedade que acelera o tempo e faz o elogio desmedido do progresso e da novidade como condições de sua felicidade.

Podemos encontrá-lo de maneira emblemática em seu Humano, demasiado humano, antecipando em mais de cem anos o arguto diagnóstico de autores como Christoph Türcke (2010) ou Byung-Chul Han (2015) em suas, sociedade excitada e sociedade do cansaço, respectivamente. Diz Nietzsche (2000, p.186) que "por falta de repouso nossa civilização caminha para uma nova barbárie. Em nenhuma outra época os ativos, isto é, os inquietos, valeram tanto. Assim, pertence às correções necessárias a serem tomadas quanto ao caráter da humanidade fortalecer em grande medida o elemento contemplativo". Ou ainda em Zaratustra: "Vós todos que amais o trabalho selvagem e o rápido, o novo, o estranho - vós vos suportais muito mal, vossa operosidade e esforço é fuga e vontade de esquecer a vós mesmos. Se acreditásseis mais na vida, vos entregaríeis menos ao instante. Mas vós não tendes conteúdo suficiente em vós para a espera - e mesmo para a preguiça, não!” (NIETZSCHE, 1977, p.82).

Como acionar o travão de emergência? Essa parece a condição necessária à restauração da nossa capacidade de pensar, de sentir e de agir na atualidade e constituem os desafios político-cognitivos a que eu quero me reportar nesta fala. Vamos a eles, então.

\section{1) reanimar o futuro [imaginar]}

O sociólogo polonês, recentemente morto - Zigmunt Bauman - teve oportunidade de dizer provocativamente, numa entrevista concedida em 2014, que estamos vivendo o "fim do futuro". 
Durante toda a era moderna, nossos ancestrais agiram e viveram voltados para a direção do futuro. Eles avaliaram a virtude de suas realizações pela crescente (genuína ou suposta) proximidade de uma linha final, o modelo da sociedade que queriam estabelecer. A visão do futuro guiava o presente. Nossos contemporâneos vivem sem esse futuro. Fomos repelidos pelos atalhos do dia de hoje. Estamos mais descuidados, ignorantes e negligentes quanto ao que virá. ${ }^{3}$

Mas ao que será que Bauman se refere quando afirma tão provocativamente estarmos vivendo o fim do futuro? Muitas são as imagens que caracterizam a atualidade como a sociedade do risco, da incerteza. Mas se do ponto de vista subjetivo todos nós, ou quase todos, partilhamos dessa sensação de aumentada incerteza e risco em relação ao futuro, do ponto de vista ontológico talvez não haja grande diferença. Quando foi que efetivamente tivemos certezas e garantias em relação ao futuro? Talvez a resposta seja nunca.

O que se alterou, muito provavelmente não é a consistência mesma do futuro, que continua tão incerta quanto antes, mas a nossa sensação subjetiva de falta de perspectiva.

Mas do que se alimenta nossa crença no futuro, senão das experiências passadas que nos levam a imaginar um desfecho possível e talvez provável? O futuro se compõe dessa capacidade de memória e de narrativa, que nos lança no futuro com maior ou menor destemor, na medida da nossa confiança no que já foi vivido e deixou marcas, rastros na nossa experiência sensível.

Aquilo a que Freud (1973) já em 1896 se referia como a obra psíquica de sucessivas épocas da vida, ou seja, narrar aquilo que nos acontece na tentativa de dar sentido, de guardar e transmitir algo que dure dessa experiência fugaz e instantânea que é o presente.

Assim, reanimar o futuro implica muito mais do que vender sonhos, promessas, promissórias. Há um risco bastante grande de se confundir reanimação do futuro com o desenho imaginário de um futuro delirante, romântico, onde a obsessão pelo "sonho" substitui a própria construção - o projeto - não deixando lugar para o presente, ou onde o projeto de futuro se torna tão obsessivo que o próprio "sonho" acaba sendo esquecido.

Como nos lembra a historiadora Carmen Leccardi (2005, p.50-51):

No interior da virtualidade que, por definição, caracteriza o futuro (o que existe em potência, mas não em ato), delineia-se, em outras palavras, um cruzamento peculiar entre a 'anarquia do futuro', e a hesitação, a ânsia, o desejo, mais ou menos subterrâneo, de substituir o projeto pelo sonho.

Há na literatura uma das figuras mais extraordinárias, a meu ver, que simboliza de certa maneira o poder desvitalizante de um "sonho" que sucumbe à obsessão do projeto. Trata-se de um dos contos de Ítalo Calvino, na sua obra Cidades Invisíveis: a cidade e o desejo número 5.

No conto, Zobeide, uma das cidades invisíveis de Ítalo Calvino (1990, p.21-22), torna-se uma cidade feia, uma armadilha, porque tão obcecados pelo futuro, os homens que "sonhavam" descuidam do presente, da vida em comum, do viver junto, afinal, daquilo que efetivamente a vida oferecia de mais interessante.

\footnotetext{
${ }^{3}$ Entrevista concedida à Revista Época, publicada em 19/02/2014. Disponível em: <http://epoca.globo.com/ideias/noticia/2014/02/bzygmunt-baumanb-vivemos-o-fim-do-futuro.html>. Acesso em: 15 abr. 2017.
} 
Naquela direção, após seis dias e sete noites, alcança-se Zobeide, cidade branca, bem exposta à luz, com ruas que giram em torno de si mesmas como um novelo. Eis o que se conta a respeito de sua fundação: homens de diferentes nações tiveram o mesmo sonho - viram uma mulher correr de noite numa cidade desconhecida, de costas, com longos cabelos e nua. Sonharam que a perseguiam. Corriam de um lado para o outro, mas ela os despistava. Após o sonho, partiram em busca daquela cidade; não a encontraram, mas encontraram uns aos outros; decidiram construir uma cidade como a do sonho. Na disposição das ruas, cada um refez o percurso de sua perseguição; no ponto em que havia perdido os traços da fugitiva, dispôs os espaços e a muralha diferentemente do que no sonho a fim de que desta vez ela não pudesse escapar. A cidade era Zobeide, onde se instalaram na esperança de que uma noite a cena se repetisse. Nenhum deles, nem durante o sono nem acordados, reviu a mulher. As ruas da cidade eram aquelas que os levavam para o trabalho todas as manhãs, sem qualquer relação com a perseguição do sonho. Que, por sua vez, tinha sido esquecido havia muito tempo.

O conto se oferece como uma rica metáfora do projeto moderno de técnica, tecnologia e ciência. O desejo que movia o sonho resulta esquecido, manifestando-se apenas em traços pálidos, numa vida que ficando escrava da fantasia de completude no futuro, perde a força do próprio desejar no presente.

Assim, a reanimação do futuro a que me refiro, envolve favorecer uma certa relação com o presente e no presente, que nos habilite a efetivamente sentir algo com a duração necessária para fazer sentido e alimentar nossa capacidade imaginativa do mundo.

Diante do crescimento desses traços ambivalentes do futuro, parece ser fundamental a capacidade de cada um/cada uma elaborar estratégias cognitivas que garantam o controle sobre o tempo da vida, a despeito do aumento da contingência: por exemplo, desenvolvendo a habilidade de imaginar uma direção ou trajetória a despeito da impossibilidade de prever seu destino final (LECCARDI, 2005, p.50-51, grifos do autor).

É também Ítalo Calvino (1998), em ensaio, quem comenta o fato de sermos bombardeados por uma tal quantidade de imagens a ponto de não podermos distinguir mais a experiência direta daquilo que vimos há poucos segundos na televisão. Em nossa memória se depositam, por traços sucessivos, mil estilhaços de imagens, semelhantes a um depósito de lixo, onde é cada vez menos provável que uma delas adquira relevo e nos auxilie a imaginar.

Uma subjetividade desvalida da capacidade de sentir e perceber o mundo e a si própria, num quadro bastante próximo daquilo que Virilio (1994, p.107) aponta como a construção de uma "'não visão', que, para alguns, parece chegar como cegueira adquirida ao longo do tempo; e, para outros, tristemente, como uma cegueira de nascença - uma privação da capacidade sensível e perceptiva -, por já terem sido imediatamente conectados, desde o nascimento, a máquinas de visão que os impedem de aprender a imaginar."

Desse modo, reanimar o futuro implicaria certa mudança na nossa relação com o presente, com a experiência do aqui-e-agora, do devir, do próprio acontecimento. Mas também certa alteração da nossa relação com o passado, com aquilo que deixa marcas, que insiste em nós pedindo passagem e sentido.

Ou seja, a reabilitação do futuro e a capacidade de imaginar envolve exercer memórias. E este é o segundo ponto, ou o segundo desafio político-cognitivo. Para além de reanimar o futuro, ou mesmo para que isso seja possível, é preciso estabelecer relação particular com o passado, ou com a memória, mais precisamente.

\section{2) exercer memórias [narrar]}

Notem que não estou me referindo a guardar memórias, como se estivéssemos tratando de uma espécie de arquivo morto a ser consultado. Trata-se de exercer memórias! Mas o que será isso? 
Vou me servir aqui de uma noção estratégica com a qual é possível dar a ver o valor da memória como força de atualização e ressignificação do presente. Essa noção é de um filósofo francês chamado Henri Bergson, e ela está situada num ensaio do final do século XIX, em 1896, intitulado Matéria e Memória.

Neste importante ensaio, Bergson (1990, p.197) nos diz que:

[...] nosso presente não deve se definir como o que é mais intenso: ele é o que age sobre nós e o que nos faz agir, ele é sensorial e é motor; nosso presente é antes de tudo o estado do nosso corpo. Nosso passado, ao contrário, é o que não age mais, mas poderia agir, e que agirá ao inserir-se numa sensação presente da qual tomará emprestada a vitalidade.

A memória, assim, dispõe dessa potência de interromper o automatismo sensório motor do presente e nos fazer percebermos a força viva da atualidade, do presente, que fica apagada por esse ímpeto automático para agir. A memória, como afirma ele, pode emprestada a vitalidade de uma sensação presente, transformando o sentido do movimento presente.

Daí a grande importância da memória da experiência como uma espécie de força intuitiva sobre o presente, que pode nos ajudar a não agirmos como autômatos que só respondem aos estímulos com o senso comum e com os clichês.

Entretanto, notem que é necessária para isso uma disposição cognitiva a que Bergson chama reconhecimento atento, em oposição ao reconhecimento automático.

$\mathrm{O}$ autor indica que o reconhecimento atento tem como princípio nos reconduzir ao objeto percebido para distinguirmos seus contornos singulares e afirmarmos sua diferença, o que caracterizaria uma efetiva cognição, em contraste com o caráter repetitivo do sistema sensório-motor. A percepção seria lançada para imagens do passado conservadas na memória, ao contrário do que acontece no reconhecimento automático, quando somos imediatamente impelidos à ação futura. Assim:

[...] enquanto no reconhecimento automático nossos movimentos prolongam nossa percepção para obter efeitos úteis e nos afastam assim do objeto percebido, aqui [reconhecimento atento], ao contrário, eles nos reconduzem ao objeto para sublinhar seus contornos. Daí o papel preponderante, e não mais acessório, que as lembrançasimagens adquirem (BERGSON, 1990, p. 78, grifo do autor).

Nessas condições, a memória deixa de ser mero arquivo ou depósito, para consagrar-se à interferência sobre o equilíbrio sensório-motor, condição primordial para a criação de novos sentidos e ruptura do senso-comum. Trata-se de uma exaltação da memória involuntária, daquilo que em nós se inscreveu como marca mnêmica, afetiva e indelével, gravada a ferro e fogo no corpo e, na maioria das vezes, à espera de uma oportunidade para manifestar-se.

De modo geral, o fenômeno do reconhecimento é visto como uma intersecção entre a percepção e a memória, rebatendo o presente sobre o passado, num jogo de analogia: o presente se incorpora ao passado ou se submete a ele. Já no caso do reconhecimento atento, o automatismo sensório-motor é freado. Memória e percepção operam em conjunto, criativamente, sem o imediato compromisso da passagem ao ato. Segundo o pensador francês, "é a memória que colore a imaginação de resíduos a priori (...) pois é dos elementos sensório-motores da ação presente que a lembrança retira o calor que lhe confere vida e é do presente que parte o apelo ao qual a lembrança responde" (BERGSON, 1990, p.125).

Tal noção aproxima-se fortemente do conceito benjaminiano de rememoração, "uma memória ativa que transforma o presente" (GAGNEBIN, 2006, p.59).

Nessa perspectiva, o reconhecimento atento tem como princípio fazer nos demorarmos nos objetos ou fenômenos percebidos para distinguirmos seus contornos singulares e afirmarmos sua 
diferença. Não simplesmente olhar com a rapidez que costumamos olhar e já responder com "opiniões" ou outro gesto, automático. Trata-se, isto sim, de nos demorarmos nos detalhes, nos deixarmos tocar pelo objeto ou pelo fenômeno, a ponto de termos nossa percepção transformada.

Isso para ele caracterizaria uma efetiva cognição, em contraste com o caráter repetitivo do sistema sensório-motor, que meramente apara estímulos e devolve respostas, num circuito acelerado e fechado em si mesmo. A percepção seria lançada para imagens do passado conservadas na memória, ao contrário do que acontece no reconhecimento automático, quando somos imediatamente impelidos à ação futura. Assim,

Nessas condições, a memória não é um mero arquivo ou depósito do passado e passa a ser essa força que quebra o equilíbrio sensório-motor, que quebra o automatismo, quebra a repetição, quebra o clichê, quebra o senso-comum. Essa é uma condição primordial para que as coisas façam sentido na minha própria vida, na minha própria história. Os acontecimentos ganham um rosto, um valor, um sentido, e podem integrar-se à minha experiência, deixando de ser meras vivências que normalmente nos passam como algo vazio ou insignificante.

Trata-se de uma exaltação da memória involuntária, criativa, daquilo que em nós se inscreveu como marca mnêmica, uma experiência que é afetiva e que não se pode apagar, gravada a ferro e fogo no corpo e que, na maioria das vezes, fica lá à espera de uma oportunidade para manifestar-se e nos ajudar na construção de uma narrativa, de uma história: a nossa narrativa, a nossa história, a tal "obra psíquica de uma vida”. Isso faz eu sentir que a vida é minha, e que eu estou ativo nela, não sou um mero espectador de mim mesmo.

Ocorre que para tal atitude cognitiva de reconhecimento atento, esta espécie particular de concentração na força do presente, na força dos afetos e das percepções, são necessárias condições favoráveis, e essas condições andam muito escassas em nossos dias.

Amamos o presente e as sensações, mas não conseguimos nos concentrar nele (o presente) e nelas (as sensações) a ponto de dar-lhes o valor merecido. Sobra-nos rapidez, velocidade, pressa e falta-nos aquilo que o Bergson chamou de duração.

Resultado: vivemos numa espécie de circuito sensório-motor acelerado que nos leva dos imaginários pré-fabricados (os clichês, os preconceitos, o senso-comum, as opiniões apressadas) para ações estereotipadas, e vice-versa. Nesse sentido, paradoxalmente, uma cultura da imagem cada vez mais presente parece esvaziar nossa própria capacidade imaginativa. A viabilidade do arquivamento quase ilimitado em suportes eletrônicos de memória contrasta com o esvaziamento das marcas da experiência, sensíveis e corpóreas, das quais dependemos para significar o presente e inventar o futuro. O filósofo e arquiteto francês Paul Virilio (1994, p.21-22), apontava com clareza tal decadência:

[...] com a multiplicação industrial das próteses visuais e audiovisuais, a utilização não-moderada destes materiais de transmissão instantânea desde a mais tenra idade, assiste-se a partir de então a uma codificação das imagens mentais cada vez mais elaborada, com a redução do tempo de retenção e sem grande recuperação posterior, uma rápida derrocada da memória.

Assim me encaminho para o terceiro e último desafio político-cognitivo ao qual desejo me reportar nesta fala: amar o presente, concentrar-se.

\section{3) amar o presente [concentrar-se]}

A relação obsessiva, francamente moderna, com a construção do futuro por meio da promessa de bem-estar individual pelo progresso nos roubou o sentido de duração do presente, ou seja, permanecer nele o tempo suficiente para que as nossas representações já estabelecidas (aquilo que também 
chamamos de senso-comum!) sejam efetivamente abaladas pelas sensações e percepções do que estamos vivendo.

O que estamos nos tornando assemelha-se muito a essa imagem da falta de medida, do exagero, do excesso. $\mathrm{O}$ excesso de informação, de opinião, de pressa, de ação automática e de arquivamento compulsivo de inutilidades, em lugar da memória ativa dos afetos. Vivemos sob os choques da excitação constante, imagética, sonora, cinestésica, que curiosa e paradoxalmente acabam nos tornando um pouco cegos, surdos e encapsulados.

Aliás, o excesso e a desproporção, segundo Nietzsche (1995, p.131), são condições de uma espécie de aleijamento, privação, empobrecimento das forças ativas da existência. Tal imagem é bastante nítida na alegórica figura do "aleijado às avessas" encontrado em "Assim falou Zaratustra".

Desde que estou entre os homens, isto me parece o mínimo do que vejo: "A este falta um olho, àquele uma orelha e a um terceiro a perna, e há outros que perderam a língua, o nariz ou a cabeça". Vi e vejo coisas piores, e várias tão abomináveis que não desejo falar de todas, mas tampouco me silenciar sobre algumas: homens aos quais falta tudo, exceto uma coisa que têm demais - homens que não são mais que um grande olho, ou uma grande boca, ou uma grande barriga, ou algo mais de grande -, aleijados às avessas, eu os chamo.

O homem padece por hipertrofia de certos sentidos em detrimento de outros, tornando-se um fardo e um limite para si mesmo. Há um diagnóstico muito preciso e certeiro do professor Philipe Dubois (2004, p.66-67), pensador da área do cinema e professor em Paris III na Sorbone que diz:

Hipertrofia do ver e do tocar, por parte de um sistema de representação tecnológica que carece cruelmente de ambos, por ter dado as costas ao Real. As telas se acumularam a tal ponto que apagaram o mundo. Elas nos tornaram cegos pensando que poderiam nos fazer ver tudo. Elas nos tornaram insensíveis pensando que poderiam nos fazer sentir tudo.

Será que estamos à altura desse amor pelo presente que pressupõe concentração e zelo com o que nos acontece? A cada dia se passam muitas coisas, porém, ao mesmo tempo, quase nada nos toca. Aliás, parece que tudo o que se passa está organizado para que nada nos aconteça efetivamente no plano da experiência. A quase impossibilidade de nos concentrarmos no presente, premidos que estamos pela incontida velocidade do capitalismo contemporâneo, priva-nos dos saberes da experiência, aqueles sem os quais a abertura à alteridade - condição do relativismo esclarecido e da transculturalidade - se torna bastante dificultada.

Esse desafio político-cognitivo de amar o presente [concentrar-se], requer favorecermos uma certa intimidade com as coisas e com os fenômenos que nos garanta a duração necessária à experiência, aquilo que marca o corpo. A valorização da experiência requer um gesto de interrupção, um modo particular de tratamento da vivência (aparentemente) comum, matéria prima das Ciências Humanas, Letras e Artes.

Há um escrito lindo da poeta carioca Ana Cristina Cesar (1998, p.156) que eu sempre imagino como uma pergunta endereçada pelo tempo presente para nós: "Por que essa falta de concentração? Se você me ama, por que não se concentra?".

Concentrar-se no presente faz parte desse conjunto de tecnologias político-cognitivas que as Ciências Humanas estão desafiadas a colocar em marcha, tanto como condições de seu próprio fazer, como tecnologias que deveriam inspirar nossos ofícios. Reabilitar as capacidades de imaginar, de narrar e de concentrar-se no presente, para que os saberes da experiência possam conquistar sua grandeza de matéria das "ciências" que são as nossas. 
Do contrário, como afirma Larrosa Bondía (2002, p.28):

Uma vez vencido e abandonado o saber da experiência e uma vez separado o conhecimento da existência humana, temos uma situação paradoxal. Uma enorme inflação de conhecimentos objetivos, uma enorme abundância de artefatos técnicos e uma enorme pobreza dessas formas de conhecimento que atuavam na vida humana, nela inserindo-se e transformando-a. A vida humana se fez pobre e necessitada, e o conhecimento moderno já não é o saber ativo que alimentava, iluminava e guiava a existência dos homens, mas algo que flutua no ar, estéril e desligado dessa vida em que já não pode encarnar-se.

A recriação de nossa relação com o tempo pressupõe um rigor ético, estético e político dos atores deste campo, no sentido de reabilitar nossa capacidade de fazer ciência que diga respeito à vida humana em sua concretude e precariedade.

\title{
3 NOTAS DE ENCERRAMENTO
}

Esses desafios político-cognitivos que apresentei aqui são uma espécie de roteiro daquilo que eu imagino poderia vir a ser nossa relação com o tempo e com a própria cidade. Me refiro aqui à cidade como a pólis grega, o espaço da vida pública, do encontro humano, do diálogo, do sonho e do projeto partilhado.

Retomo Wolfgan Welsch, do começo da minha fala, ao afirmar que a função social das Ciências Humanas, e também das Letras e das Artes, depende da afirmação de novas condições internas da própria ciência: capacidade de relativismo esclarecido e diálogo transdisciplinar.

Para isso, entretanto, parece necessário colocar em ação atitudes político-cognitivas bastante escassas entre nós em tempos de tamanha aceleração e competitividade: reanimar o futuro, exercer memórias e amar o presente, com toda a concentração e o cuidado que ele merece. Esses são desafios para a viagem e não para a chegada! Nossa atenção e fruição dos processos em lugar da corrida desenfreada em direção aos produtos pode ser uma boa "trava de emergência", como queria Benjamin, nesse comboio desenfreado que nos tornamos.

Quero terminar com outros dois apelos às letras, ao poder das narrativas, da Literatura, para pensar o tempo. O primeiro trata-se de um singelo (e brilhante) recorte de uma fala do professor e crítico literário Antônio Cândido (2006, s/p) - recentemente falecido - por ocasião da inauguração da biblioteca Florestan Fernandes em 2006, e refere-se brilhantemente ao tempo, elemento central da problemática aqui demarcada:

\begin{abstract}
Acho que uma das coisas mais sinistras da história da civilização ocidental é o famoso dito atribuído a Benjamim Franklin, "tempo é dinheiro". Isso é uma monstruosidade. Tempo não é dinheiro. Tempo é o tecido da nossa vida, é esse minuto que está passando. Daqui a 10 minutos eu estou mais velho, daqui a 20 minutos eu estou mais próximo da morte. Portanto, eu tenho direito a esse tempo. Esse tempo pertence a meus afetos. É para amar a mulher que escolhi, para ser amado por ela. Para conviver com meus amigos, para ler Machado de Assis. Isso é o tempo. E justamente a luta pela instrução do trabalhador é a luta pela conquista do tempo como universo de realização própria. A luta pela justiça social começa por uma reivindicação do tempo: "eu quero aproveitar o meu tempo de forma que eu me humanize". ${ }^{4}$
\end{abstract}

O segundo remonta aos clássicos, não menos emblemático.

\footnotetext{
4 Disponível em: <http://www.cartamaior.com.br/?/Editoria/Movimentos-Sociais/Antonio-Candido-inaugura-biblioteca-doMST>. Acesso em: 15 abr. 2017.
} 
Refiro-me à viagem arquetípica de Ulisses, que durante vinte anos fica fora de Ítaca, sua ilha, onde Penélope lhe espera. Dez anos de ida à tróia, e dez anos de retorno. Ulisses sonha em voltar para Penélope. Mas há um episódio da Odisséia em particular, em que Ulisses desembarca na ilha de Calypso. Calypso, a deusa mais bela e o seu reino o mais luxuoso e deslumbrante jamais descrito: o verdor permanente, o florescimento, os aromas das flores, as paisagens idílicas, a cor do mar. Em Calypso as pessoas não envelhecem, há o fulgor dos anos, não há doença, não há dor, não há sofrimento. Não obstante, Ulisses vivendo neste paraíso e Calypso o surpreende na praia, olhando o mar, o horizonte, melancólico! Com o rosto apoiado na mão e sonhando com Penélope, na sua doce Ítaca. E ela, então, tomada de piedade, lhe manda partir.

Encontramos em Konstantino Kaváfis (2006, p.101-103) uma linda manifestação poética de tal condição. E com ela encerro minha intervenção, desejoso de que encontremos na poesia forças de composição para nossas lidas no campo das ciências humanas, das letras e das artes. Os desafios de voltar a imaginar, narrar e amar o presente parecem constituir um bom roteiro de trabalho para o ano que continua começando, a cada dia. Diz ele:

Quando partires em viagem para Ítaca faz votos para que seja longo o caminho, pleno de aventuras, pleno de conhecimentos.

Os Lestrigões e os Ciclopes, o feroz Poseidon, não os temas, tais seres em teu caminho jamais encontrarás, se teu pensamento é elevado, se rara emoção aflora teu espírito e teu corpo. Os Lestrigões e os Ciclopes, o irascível Poseidon, não os encontrarás, se não os levas em tua alma, se tua alma não os ergue diante de ti.

Faz votos de que seja longo o caminho. Que numerosas sejam as manhãs estivais, nas quais, com que prazer, com que alegria, entrarás em portos vistos pela primeira vez; para em mercados fenícios e adquire as belas mercadorias, nácares e corais, âmbares e ébanos e perfumes voluptuosos de toda espécie, e a maior quantidade possível de voluptuosos perfumes; vai a numerosas cidades egípcias, aprende, aprende sem cessar dos instruídos.

Guarda sempre Ítaca em teu pensamento.

É teu destino aí chegar.

Mas não apresses absolutamente tua viagem.

É melhor que dure muitos anos e que, já velho, ancores na ilha, rico com tudo que ganhaste no caminho, sem esperar que Ítaca te dê riqueza.

Ítaca deu-te a bela viagem.

Sem ela não te porias a caminho.

Nada mais tem a dar-te.

Embora a encontres pobre, Ítaca não te enganou.

Sábio assim como te tornaste, com tanta experiência, já deves ter compreendido o que significam as Ítacas. 
As Ítacas são nossos motivos para seguir viagem. E a viagem mesma é o próprio presente! Muito obrigado pela atenção dos senhores.

\section{REFERÊNCIAS}

BENJAMIN, Walter. O anjo da história. Lisboa: Assírio \& Alvim, 2010.

BERGSON, Henri. Matéria e memória. Trad. Paulo Neves. São Paulo: Martins Fontes, 1990

CALVINO, Italo. Seis propostas para o próximo milênio. São Paulo: Companhia das Letras, 1998.

CALVINO, Ítalo. As cidades invisíveis. São Paulo: Companhia das Letras, 1990.

CESAR, Ana Cristina. A teus pés. São Paulo: Editora Ática, 1998.

DUBOIS, Philippe. Cinema, vídeo, Godard. Trad. Mateus Araújo Silva. São Paulo: Cosac Naify, 2004.

FREUD, Sigmund. "Carta 52" [1896]. In: Obras Completas. Madrid. Ed. Biblioteca Nueva, 1973.

GAGNEBIN, Jeanne Marie. Lembrar escrever esquecer. São Paulo: Ed.34, 2006.

GIACOIA JUNIOR, Oswaldo. Sonhos e pesadelos da razão esclarecida: Nietzsche e a modernidade. Passo Fundo: UPF, 2005.

HAN, Byung-Chul. Sociedade do cansaço. Petrópolis: Vozes, 2015.

KAVÁFIS, Konstantinos. Poemas de K. Kaváfis. Tradução, estudo e notas de Ísis Borges da Fonseca. São Paulo: Odysseus, 2006.

LARROSA BONDIA, Jorge. Notas sobre a experiência e o saber de experiência. Rev. Bras. Educ., Rio de Janeiro, n. 19, p. 20-28, Apr. 2002.

LECCARDI, Carmen. Por um novo significado do futuro: mudança social, jovens e tempo. Trad. Norberto Luiz Guarinello. Tempo Social, Revista de Sociologia da USP, v. 17, n. 2, 2005

NIETZSCHE, Friedrich. Assim falou Zaratustra (tradução de Mário da Silva). São Paulo: Civilização Brasileira, 1977.

NIETZSCHE, Friedrich. Humano Demasiado Humano (tradução de Paulo Cezar de Souza). São Paulo: Companhia das Letras, 2000.

TÜRCKE, Christoph. Sociedade excitada: filosofia da sensação. Tradução: Antonio A. S. Zuin et al. Campinas: Ed. UNICAMP, 2010.

VIRILIO, Paul. A máquina de visão. Rio de Janeiro: José Olímpio, 1994. 
WELSCH, Wolfgang. Estetização e estetização profunda: ou a respeito da atualidade do estético nos dias de hoje. In PORTO ARTE. Porto Alegre, v.6, n.9, p.7-22, mai. 1995.

WELSCH, Wolfgang. Mudança estrutural nas ciências humanas: diagnóstico e sugestões.

In: Educação. Porto Alegre, ano XXX, n. 2 (62), p. 237-258, mai./ago. 2007. 